Иконников Е. А., Иконникова А. Е., Кизиль Е. В.

E. A. Ikonnikov, A. E. Ikonnikova, E. V. Kizil'

ИСПОЛЬЗОВАНИЕ АУТСОРСИНГА НА ПРЕДПРИЯТИЯХ ЖЕЛЕЗНОДОРОЖНОГО TРАНСПОРТА

\title{
USE OF OUTSOURCING AT RAILWAY ENTERPRISES
}

Иконников Егор Алексеевич - студент магистратуры факультета экономики и менеджмента (кафедра экономики, финансов и бухгалтерского учёта) (Россия, Комсомольск-на-Амуре); 681013, Хабаровский край, г. Комсомольск-на-Амуре, пр. Ленина, 27. E-mail: ikonnikov.kms@gmail.com.

Mr. Egor A. Ikonnikov - Master' s Degree student, Faculty of Economics and Management, Economics, Finance and Accounting Department (Russia, Komsomolsk-on-Amur); 681013, Khabarovsk territory, Komsomolsk-onAmur, 27 Lenin str. E-mail: ikonnikov.kms@gmail.com.

Иконникова Анастасия Евгеньевна - студентка магистратуры факультета экономики и менеджмента (кафедра экономики, финансов и бухгалтерского учёта) (Россия, Комсомольск-на-Амуре); 681013, Хабаровский край, г. Комсомольск-на-Амуре, пр. Ленина, 27. E-mail: lisa_dilan@mail.ru.

Ms. Anastasia E. Ikonnikova - Master' s Degree student, Faculty of Economics and Management, Economics, Finance and Accounting Department (Russia, Komsomolsk-on-Amur); 681013, Khabarovsk territory, Komsomolsk-on-Amur, 27 Lenin str. E-mail: lisa_dilan@mail.ru.

Кизиль Елена Витальевна - доктор экономических наук, профессор кафедры экономики, финансов и бухгалтерского учёта Комсомольского-на-Амуре государственного университета (Россия, Комсомольск-наАмуре); 681013, Хабаровский край, г. Комсомольск-на-Амуре, пр. Ленина, 27; тел.: + 7 (914) 179-42-20. E-mail: kisil_ev@mail.ru.

Ms. Elena V. Kizil' - Doctor of Economics, Professor, Economics, Finance and Accounting Department, Komsomolsk-on-Amur State University (Russia, Komsomolsk-on-Amur); 681013, Khabarovsk territory, Komsomolskon-Amur, 27 Lenin str.; tel.: + 7 (914) 179-42-20. E-mail: kisil_ev@mail.ru.

Аннотация. В статье рассмотрены основные направления деятельности ОАО «Российские железные дороги», переданные в настоящее время на аутсорсинг. Исследованы теоретические вопросы становления аутсорсинга, цели и задачи внедрения в практику инфраструктурной компании, преимущества, сложности и недостатки перехода на аутсорсинг. Представлена методика оценки эффективности использования аутсорсинга, условия её применения на предприятиях железнодорожного транспорта.

Summary. The article discusses the main areas of activity of JSC «Russian Railways», which are currently outsourced. The theoretical issues of the development of outsourcing, the goals and objectives of implementing the infrastructure company in the practice, the advantages, difficulties and disadvantages of the transition to outsourcing are investigated. A methodology for assessing the effectiveness of using outsourcing, the conditions for its use at railway transport enterprises is presented.

Ключевые слова: аутсорсинг, бизнес-процессы, эффективность, российские железные дороги.

Key words: outsourcing, business processes, efficiency, Russian railways.

\section{УДК 338:47}

Для эффективной работы предприятия любого уровня очень важным моментом в организации производственного процесса является правильное распределение ресурсов. Это требует поддерживания на высоком уровне большого количества вспомогательных служб и подразделений (технико-экономические отделы, бухгалтерия, кадры, обслуживающие подразделения, IT-структуры и т. д.). Большую роль в данном направлении играет использование аутсорсинга как способа высвобождения от определённых функций - организационных, финансовых и т. д. В ре- 
Иконников Е. А., Иконникова А. Е., Кизиль Е. В.

ИСПОЛЬЗОВАНИЕ АУТСОРСИНГА НА ПРЕДПРИЯТИЯХ ЖЕЛЕЗНОДОРОЖНОГО ТРАНСПОРТА

зультате компания получает возможность экономить на трудовых ресурсах, требующих большого внимания и финансовых вложений.

Аутсорсинг существовал ещё со времён разделения труда, но широкое применение данное направление менеджмента получило лишь в конце 80-х - начале 90-х годов XX века. В настоящее время многие компании, изучив опыт зарубежных коллег, начали успешно применять аутсорсинг, отказываясь от самостоятельного ведения каких-либо видов деятельности, мешающих осуществлению основных функций.

Несмотря на довольно широкое использование аутсорсинга, принятие решения о его применении является по-прежнему сложной задачей, поскольку затрагивает стратегические интересы компании.

Аутсорсинг (от англ. outsourcing: out-source-using) - буквально трактуется как «использование внешних ресурсов» и «внешних источников». Существует несколько определений аутсорсинга.

Например, в современных экономических словарях под аутсорсингом понимается передача стороннему исполнителю некоторых непрофильных функций предприятия с целью повышения производительности труда, снижения себестоимости продукции и услуги в основном за счёт использования более дешёвой рабочей силы, привлекаемой со стороны [1].

Концепция аутсорсинга активно развивалась во времена Генри Форда. В своей книге «Моя жизнь. Мои достижения» он описывает, как дотошно рассчитывал, дешевле покупать ту или иную деталь или производить её самим [2].

Вопросам применения аутсорсинга посвящено значительное количество работ зарубежных и отечественных авторов: Е. Аксенова, Б. А. Аникина, П. Готтшальк, М. Доннеллан, Л. С. Казанцева, Т. В. Никонова, У. Росс, Як Финценц. Большое внимание данному явлению уделено в работах учёных и специалистов, относящихся к сфере управления, экономики и финансов железнодорожного транспорта (А. В. Андреев, А. Н. Бессонова, Н. П. Веретенников, И. А. Епишкин, Р. Г. Леонтьев, В. П. Шабалин и др.) [3].

Согласно мировой классификации существует аутсорсинг непроизводственной сферы (управление персоналом, бухгалтерский налоговый учёт и аудит, управленческие услуги, сервисные услуги и т. д.), производственного сектора экономики (вспомогательно-заготовительные, вспомогательно-производственные, сборочные, пуско-наладочные процессы; контроль качества продукции; отгрузка и сбыт продукции и т. д.), а также аутсорсинг информационных технологий (разработка программного обеспечения, хостинг СУБД-коммуникационных систем, хостинг вебсервисов, предоставление интернет-услуг, программного обеспечения и др.) [4].

Впервые в России об аутсорсинге на железнодорожном транспорте заговорили на семинаре в г. Ростове-на-Дону в 2004 году. В 2005 году аналогичный семинар был проведён в г. Екатеринбурге, а в 2005 году в г. Щербина прошла выставка «Аутсорсинг и снабжение железнодорожного транспорта», где был организован круглый стол, на котором обсуждались вопросы необходимости создания перспективной программы внедрения аутсорсинга на железнодорожном транспорте [5].

Основными документами, регулирующими взаимоотношения аутсорсинговых компаний и ОАО «Российские железные дороги», являются «Положение об использовании аутсорсинга филиалами ОАО “РЖД”», «Положение о порядке использования сетевого аутсорсинга в ОАО “РЖД”», «Стратегия развития железнодорожного транспорта в Российской Федерации до 2030 года». Как отмечается в этих документах, главной задачей в решении проблемы повышения эффективности функционирования железнодорожного транспорта является снижение совокупных транспортных издержек.

При использовании аутсорсинга на железнодорожном транспорте планируется достижение следующих целей [5]:

- повышение экономической эффективности деятельности предприятия и снижение затрат на ведение организационной и хозяйственной деятельности;

- снижение затрат на непрофильные направления компании;

- создание условий для удовлетворения сезонной потребности в дополнительном персонале;

- повышение качества выполненных работ, услуг, переданных на аутсорсинг. 


\section{Учёные записки}

Комсомольского-на-Амуре государственного технического университета

Применение аутсорсинга в рамках пассажирского комплекса помогает решить задачи сезонных пиков перевозок. Кроме того, осуществляется передача непрофильных функций внешним специализированным фирмам. Например, мойкой вагонов, уборкой производственных и служебных помещений занимаются специализированные клиринговые фирмы, у которых себестоимость уборки одного метра площади намного ниже.

Актуальным на железнодорожном транспорте является использование аутсорсинга в пассажирском комплексе не только в сфере обслуживания вагонов в пути следования (проводники, постельное бельё, уборка, питание), но и в организации отдельных видов пассажирских перевозок.

На сегодняшний день на железной дороге существуют 90 аутсорсинговых фирм: Московская, Горьковская, Северо-Кавказская, Свердловская, Красноярская, Западно-Сибирская, Восточно-Сибирская и Дальневосточная (70 \% проводников выведены в аутсорсинг). Количество выведенных из штата и переданных на аутсорсинг работников - 30,8 тыс. чел. (2017 год), в том числе 18,6 тыс. чел. - проводников [7].

В ОАО «Российские железные дороги» аутсорсинг осуществляется по 80 позициям по 9 департаментам в сфере пассажирских перевозок (проводники, экипировка, уборка и мойка, биотуалеты), в сфере грузовых перевозок (обслуживание автопогрузчиков «Кальмар» и «Тойота», тарноштучные грузы, обслуживание вагонных весов, автоматизированной системы коммерческого осмотра вагонов (АСКО 118)).

Применение аутсорсинга на предприятиях железнодорожного транспорта позволяет повысить производительность труда и экономических показателей деятельности за счёт снижения численности штата лишь формально. Однако следует отметить, что передача технологических процессов и функций на аутсорсинг, который требует присутствия высококвалифицированных сотрудников без ущерба для подразделений железнодорожного транспорта, невозможна. Исключение составляет привлечение работников в организации пассажирского скоростного и высокоскоростного сообщения. Укомплектование поездных бригад проводниками пассажирских вагонов в летнее время происходит за счёт привлечения студентов учебных заведений ОАО «Российские железные дороги». Это способствует выполнению поставленных задач предприятия в нужные сроки и в соответствии с требуемыми объёмами работ.

Несмотря на широкое применение аутсорсинга на железных дорогах его использование не всегда можно считать оптимальным, поскольку в ряде случаев на аутсорсинг выводятся виды деятельности и работы, передача которых приводит к увеличению издержек ОАО «Российские железные дороги».

В ОАО «Российские железные дороги» разрешены к использованию два вида аутсорсеров:

- организация-аутсорсер, которая оказывает незначительное количество работ (услуг);

- сетевой аутсорсер - специализированная организация, обладающая большим опытом в области выполнения отдельных видов работ (услуг), необходимым производственным потенциалом и имеющая структурные подразделения, обеспечивающие не менее 75 \% охвата территории сети железных дорог [8].

В настоящее время ОАО «Российские железные дороги» стремится к снижению количества компаний-аутсорсеров, взаимодействующих по контрактам. Взаимодействие планируется строить по принципу «один аутсорсер на каждое отделение дороги или в региональной дирекции». Вторым признаком, влияющим на выбор компании-аутсорсера, служит низкая стоимость и высокое качество работ (услуг), а также наличие опыта работы на предприятиях железнодорожного транспорта [8].

Очень важно, чтобы на рынке аутсорсеров существовала конкуренция. В случае ненадлежащего выполнения аутсорсером своих обязанностей в соответствии с условиями контракта договор может быть расторгнут и заключён с новым аутсорсером.

Насыщение рынка аутсорсеров очень важно для ОАО «Российские железные дороги», так как в силу специфики его деятельности сложно найти компанию, отвечающую всем требованиям по выполнению соответствующих работ. Большее количество аутсорсинговых фирм необходимо на случай банкротства конкурирующей компании [9]. 
В филиалах ОАО «Российские железные дороги» передача персонала компании (аутстаффинг) аутсорсинговым компаниям осуществляется с согласия работника на перевод в другую компанию с сохранением средней заработной платы, исчисленной по прежнему месту работы. Приём новых работников осуществляется на условиях аутсорсера по расчётной стоимости чел/час.

При передаче функций или бизнес-процессов в иную компанию чаще всего происходит реорганизация деятельности сотрудников, поэтому основная цель любой компании - это облегчение процесса адаптации сотрудников к новым условиям [3].

Следует отметить, что внедрение аутсорсинга, несмотря на множество положительных качеств, имеет ряд отрицательных моментов:

- невозможность чёткого и правильного управления данными взаимоотношениями;

- низкий уровень обоснованности принятия решений вследствие недостаточности, с одной стороны, специализированных инструментов планирования, а с другой - оценки социальных, экономических и финансовых последствий их реализации;

- отсутствие чётко разработанных методов оценки существующих аутсорсинговых взаимоотношений;

- низкий уровень квалификации сотрудников компании-аутсорсера [10].

Значительно уменьшить количество указанных недостатков позволяет методика экспертной оценки бизнес-процессов ОАО «Российские железные дороги», разработанная самой компанией [11].

Экономическим обоснованием перехода на аутсорсинг, согласно данной методике, является оценка бизнес-процессов (БП) по критериям передачи на аутсорсинг и определение индекса важности БП для ОАО «Российские железные дороги» $\left(I_{\mathrm{B}} \Sigma i\right)$ и индекса эффективности $\left(I_{\text {э }} \Sigma i\right)$ для $i$-го эксперта.

Алгоритм определения данных индексов начинается с заполнения таблицы экспертной оценки бизнес-процессов, которая составляется подразделением-инициатором (см. табл. 1).

Таблица 1

Экспертная оценка бизнес-процессов

\begin{tabular}{|c|c|c|c|c|c|c|}
\hline \multirow{2}{*}{ Группы критериев } & \multirow{2}{*}{$\begin{array}{l}\text { Наименование критерия } \\
\text { передачи на аутсорсинг }\end{array}$} & \multicolumn{5}{|c|}{ Балльная экспертная оценка } \\
\hline & & 0 & 1 & 2 & 3 & 4 \\
\hline \multirow{4}{*}{$\begin{array}{l}\text { 1. Определение уровня важности } \\
\text { БП для ОАО «РЖД» }\left(I_{\mathrm{B}}\right)\end{array}$} & 1,1 & & & & & \\
\hline & 1,2 & & & & & \\
\hline & 1,3 & & & & & \\
\hline & - & & & & & \\
\hline \multirow{4}{*}{$\begin{array}{l}\text { 2. Сравнение эффективности БП } \\
\text { с рынком }\left(I_{\ni}\right)\end{array}$} & 1,1 & & & & & \\
\hline & 1,2 & & & & & \\
\hline & 1,3 & & & & & \\
\hline & - & & & & & \\
\hline
\end{tabular}

В результате по каждому критерию формируется экспертное мнение относительно возможности передачи рассматриваемого БП на аутсорсинг.

Индекс важности БП для ОАО «Российские железные дороги» и индекс эффективности БП для $i$-го эксперта определяется как среднее арифметическое всех балльных оценок соответствующих групп критериев:

$$
\begin{aligned}
& I_{\mathrm{B}} \sum i=\frac{1}{13} \cdot \Sigma_{1}^{13} I_{\mathrm{B}}, \\
& I_{\mathrm{B}} \sum i=\frac{1}{12} \cdot \Sigma_{1}^{12} I_{\ni},
\end{aligned}
$$




\section{Учёные записки}

Комсомольского-на-Амуре государственного технического университета

где $I_{\mathrm{B}}$ - балльная оценка критерия передачи на аутсорсинг, относящегося к группе «Определение уровня важности БП для ОАО "Российские железные дороги"», произведённая $i$-м экспертом; $i-$ порядковый номер эксперта; $I_{\ni}$ - балльная оценка критерия передачи на аутсорсинг, относящегося к группе «Сравнение эффективности БП с рынком», произведённая $i$-м экспертом.

В качестве методики экспертной оценки бизнес-процессов ОАО «Российские железные дороги» рекомендуется выбирать количество критериев, относящихся к группе «Определение уровня важности БП для ОАО “РЖД”», равным 13; а относящихся к группе «Сравнение эффективности БП с рынком»- равным 12.

Результат оценки индексов важности и индексов эффективности БП позволит выделить только те процессы, которые будут наиболее выгодны при их ликвидации в филиалах и структурных подразделениях ОАО «Российские железные дороги» и покупке готовых результатов на рынке (у лидеров отрасли). В частности, для Дальневосточной железной дороги - филиала ОАО «РЖД»- такими процессами являются:

- производство работ по замене стрелочных переводов, переустройству мостовых пролётов, установке вагонных замедлителей, погрузке (выгрузке) тяжеловесных грузов, демонтажу зданий и сооружений и так далее, выполняемых восстановительным поездом (дирекция аварийновосстановительных работ);

- организация и проведение лабораторных испытаний качества веществ, материалов и иной продукции при поступлении и хранении на Дальневосточной железной дороге;

- организация и проведение химических, физических, физико-химических, электротехнических, металлографических лабораторных испытаний различных веществ и материалов, применяемых при ремонте и эксплуатации подвижного состава и других технических средств железнодорожного транспорта в границах Дальневосточной железной дороги (дорожная химико-техническая лаборатория).

Таким образом, аутсорсинг на предприятиях железнодорожного транспорта имеет как положительные, так и отрицательные стороны его применения. В данном случае очень многое зависит от компании, которая заключает договор с организацией-аутсорсером. При заключении такого договора предприятие должно чётко ставить перед собой цели и понимать, сможет ли оно при переходе на аутсорсинг достичь заветного результата. Экономическому обоснованию перехода на аутсорсинг способствует применение методики экспертной оценки бизнес-процессов ОАО «Российские железные дороги», которая позволяет сформировать предварительную оценку по возможности выведения БП из деятельности подразделения и его замещения рыночной услугой.

\section{ЛИТЕРАТУРА}

1. Курбанов, А. Х. Аутсорсинг: история, методология, практика: моногр. / А. Х. Курбанов, В. А. Плотников М.: ИНФРА-М, 2012. $-112 \mathrm{c}$.

2. Форд, Г. Моя жизнь. Мои достижения / Г. Форд. - СПб.: Астрель, 2013. - 352 с.

3. Аутсорсинг. Аренда персонала: правовые основы, бухгалтерский учёт и налогообложение: практ. руководство; под общ. ред. Ю. Л. Фадеева. - М.: Эксмо, 2007. - 80 с.

4. Андрякова, Т. В. Методические основы классификации аутсорсинга / Т. В. Андрякова, П. В. Бринь // Вестник НТУ «ХПИ». Актуальные проблемы управления. - 2011. - № 38. - С. 3-8.

5. Гончар, С. Н. Повышение эффективности использования имущества, непрофильной сферы железнодорожного транспорта: дис. на соиск. учён. степ. канд. экон. наук: 08.00.05 / Гончар Светлана Николаевна. Хабаровск, 2006. - 133 с.

6. Аникин, Б. А. Аутсорсинг и аутстаффинг: высокие технологии менеджмента: учеб. пособие / Б. А. Аникин, И. Л. Рудая. - М.: ИНФРА-М, 2007. - 288 с.

7. Годовой отчёт ОАО «РЖД» за 2017 год [Электронный ресурс] / Департамент корпоративных финансов ОАО «РЖД». - М.: Пресс-служба ОАО «РЖД», 2018 год. - Режим доступа: https://ar2017.rzd.ru/ (дата обращения: 28.05.2019).

8. Казанцева, Л. С. Актуальные проблемы применения аутсорсинга на железнодорожном транспорте [Электронный ресурс] / Л. С. Казанцева // Теория управления. - 2011. - № 4. - Режим доступа: http://www.uecs.ru/uecs-28-282011/item/421-2011-05-23-07-16-42 (дата обращения: 05.03.2019). 
Иконников Е. А., Иконникова А. Е., Кизиль Е. В.

ИСПОЛЬЗОВАНИЕ АУТСОРСИНГА НА ПРЕДПРИЯТИЯХ ЖЕЛЕЗНОДОРОЖНОГО ТРАНСПОРТА

9. Йордон, Э. Аутсорсинг: конкуренция в глобальной гонке за производительностью / Э. Йордон. - М.: Лори, 2006. -367 с.

10. Готтшальк, П. ИТ-аутсорсинг: построение взаимовыгодного сотрудничества / П. Готтшальк, Х. СолиСетер. - М.: Альпина Бизнес Букс, 2007. - 390 с.

11. Об утверждении методики экспертной оценки бизнес-процессов ОАО «РЖД» по критериям передачи на аутсорсинг [Электронный ресурс]: распоряжение ОАО «РЖД» от 31 января 2018 г. № 173-р. - Доступ из справ.-правовой системы «КонсультантПлюс». - Режим доступа: www.consultant.ru (дата обращения: 15.04.2019). 